\title{
Exploring UX Maturity in Software Development Environments in Saudi Arabia
}

\author{
Obead Alhadreti \\ Department of Computer Sciences, Computing College \\ Umm Al-Qura University, Al-Qunfudah, Saudi Arabia
}

\begin{abstract}
User experience (UX) design is becoming increasingly crucial for developing successful software today. It can determine whether or not users stay engaged with a product or service. It is, therefore, important that organizations have their users in mind when developing software and that there is a maturity for UX work. However, there are still organizations which do not value UX highly and where UX maturity is low. This paper reported the results of a survey of 75 practitioners working in software-development environments in Saudi Arabia. The survey was conducted in July 2020 and aimed to explore practitioners' perceptions of UX maturity, UX significance, and the challenges that face $U X$ process in software development environments. The results show a higher than expected perception of organizational UX maturity amongst the practitioners surveyed, with the majority considering their organizations to be at an "Integrated phase". The degree of awareness of UX value was also found higher than anticipated. Furthermore, the study reveals important information about the most used UX methods as task analysis, prototyping, and heuristic evaluation. It also shows that UX assessment and user involvement being considered during different stages of product development, particularly in the prototyping phase. The major challenges that face UX process were found to be the need to improve UX consistency and the ability of teams and departments to collaborate.
\end{abstract}

Keywords-User experience; UX maturity; Saudi Arabia

\section{INTRODUCTION}

Organizations are increasingly recognizing the business value of hiring user experience (UX) professionals and incorporating UX design. Indeed, high-profile companies such as Apple and Google have incorporated UX design as a centerpiece of their success. The demand for UX specialists in the industry is leading to increasing numbers of related courses at universities around the world, and there are more and more people trained and capable of excellence in UX design. However, a belief in UX and having UX skills and resources available are not sufficient to guarantee meeting corporate goals for UX design. The UX of a product is not solely down to a UX designer; it is a result of how the organization as a whole executes on the product creation. There is, therefore, an implied sentiment that more mature UX leads to organizational success [1].

The information and communications technology (ICT) sector is growing fast in Saudi Arabia. It currently constitutes one of the Middle East's largest markets for telecoms and information technology. The Saudi Arabian Communications and Information Technology Commission (CITC) has stated that spending in the ICT sector has reached approximately USD35 billion in 2020, a growth of approximately $8.3 \%$ over 2015, due to digital-transformation initiatives employed by a number of organizations around the country [2]. Digital services are also rapidly growing due to the increase in the Internet penetration rates and mobile phone usage. Approximately 29.9 million people in Saudi Arabia were using the Internet by the end of 2018. Mobile phone penetration is at $130 \%$, with 42.5 million subscribers [3].

The Saudi Arabian Government's National Transformation Program has also played a role in enabling the IT industry to enhance its contribution to the non-oil component of the country's gross domestic product (GDP) [4]. There were 1650 IT companies in the country in 2003, encompassing homegrown businesses as well as multinationals and local subsidiaries, and this figure has increased substantially. Then, there was only a few local IT companies which involved themselves in system development, which might be due to individuals and organizations preferring outsourced solutions [5]. Today, there are indications of organizations having already moved away from complete reliance on outsourcing and becoming providers of a proportion of services and products. That could be down to Saudi Arabian businesses preferring IT services tailored to local requirements, which can be achieved by companies located inside the country. It has also been noted that organizations in both the public and private sectors have developed in-house technology development resources, which may explain why one of commonest jobs in IT currently is "software developer," and why there is an expectation that the specialty will continue to have high demand [6]. Furthermore, there is an everincreasing number of courses and educational programs in UX design on offer at Saudi universities and other educational institutions. Likewise, there are more and more research centers and research departments engaged with the UX field [7].

With these growth indicators of the software industry and an increasing UX attention in education establishments, there is surprisingly little data about where the UX field currently stands in Saudi Arabia, what impact the increasing attention on UX has had on IT development in practice, what challenges UX facing. It appears that no study inspected UX maturity in Arab countries, where software-development environments may have different cultural and organizational standards, and societies have different cultural and local requirements of software products. This paper presents and discusses results from a survey of practitioners' perceptions of 
UX maturity, and UX significance, and the challenges that face UX process in software development environments in Saudi Arabia. The paper is structured as follows. Section II reviews existing literature, with attention given to recent studies around UX maturity models. Later sections present the study's methodology, data analysis and its results. The final section sets out the conclusions drawn from the study.

\section{RELATED WORK}

Studies of UX maturity have mainly focused on Europe and the USA. Rukonić, de Meerendré, and Kieffer [1] assessed four dimensions of UX maturity and capability, namely methods, resources, artefacts, culture and literacy. As a demonstration of how their model could be used, the researchers undertook a case study across four corporations. The data collection was carried out by means of a survey, which was made up of questionnaire, completed on-line, and interviews conducted remotely. A selection of the survey participants was interviewed to corroborate their survey answers, establish their level of UX literacy, and elicit their opinions of the value of UX in assisting with product development. There was a particular focus on how return on the investment in UX was understood by the participants and on how UX discipline was viewed by their employers. The results seem to accurately capture the current UX capability of an organization.

Anchahua, Garnique, and Tarazona [8] developed a UX maturity model that provides tools, practices and techniques to enhance user satisfaction and corporate revenue. To test the model, the authors used a checklist of 25 tools, applied to four web-based software applications, to assess their value in enhancing the user experience. Half of these tools demonstrated greater maturity, as was also seen in the measures of user satisfaction and usability. The model was subsequently tested on an e-commerce website, which initially scored maturity of $38 \%$. This score rose to $67.5 \%$ following the application of the checklist.

Another study, Möller [9], studied an organization which found UX difficult to accommodate within its work routines. This was in part due to using agile methods of software development at the same time. Nielsen's eight-stage model was used to test the organization's UX maturity. A survey with questions based on the model was used to collect data. A series of five interviews, run in a semi-structured format, was used to follow this up. The study results indicated that the organization had reached no higher than stage four maturity, and that was in projects where there was a plan and budget for UX and where teams had specific UX roles. Other teams had a lower maturity level. The authors then discussed ways in which the organization could improve its UX maturity. The actions recommended consisted of planning for UX, finding a way to show UX results, allowing UX experts to take the lead, involving actual users, and structuring the work on UX around agile processes.

The first empirical study of UX maturity across diverse people and organizations was that carried out by Sauro, Johnson, and Meenan [10]. The authors described the first steps of a maturity model based upon empirical evidence and what they learned from surveys of practitioners in many organizations and from a series of interviews with experienced UX professionals. This empirically based methodology was shown by the results to be sufficiently flexible and intelligible for application in a broad spectrum of sectors and organizations. The assessment tool itself was a survey employing eleven measures:

- characteristics of the individual user;

- characteristics of the organization;

- $\quad$ staff involved in UX;

- methods for UX research;

- corporate culture and leadership;

- degree of integration of UX;

- skills and training related to UX;

- product success;

- business success;

- the budget and resources for UX; and

- challenges associated with and future directions for UX.

Young, Chao, and Chandler [11] perform a mixedmethods study of maturity of UX practice in academic libraries. Both qualitative analysis of the content and statistical analysis were applied to data from a survey carried out amongst UX practitioners. The results showed the extent and types of UX methods used by practitioners at the present time in academic libraries. Responses to the survey also allowed the extraction of a series of themes that reveals the factors influencing UX maturity. The authors' analysis looked in particular at the corporate characteristics influencing methods and maturity of UX. A maturity scale tailored for libraries was thereby developed and recommendations were made towards practices that could enhance academic libraries' UX maturity.

It is worth mentioning that, although there is variation in the names and structures of models designed to evaluate UX maturity, these models generally comprise between five and seven levels, which go from "unrecognized" up to "institutionalized," following a pattern along the lines of the pioneering "Organizational Human-Centeredness Scale" developed by Jonathan Earthy [12]:
1) Unrecognized
2) Recognized
3) Considered
4) Implemented
5) Integrated
6) Institutionalized.

Prior studies have also investigated perceptions of the significance of user-centered design (UCD) and UX amongst practitioners. Vredenburg, Mao, Smith, and Carey [13] surveyed UCD practitioners and reported that a large proportion of them supported the statement that "UCD ways of working had produced significant impacts in product development, as well as enhancing their companies' products' usability and usefulness”. Ji and Yun [14] agreed with [13] 
that the UCD and usability practitioners surveyed supported the perception of UCD methods becoming more popular and more likely to be widely adopted in the future. Likewise, in a study of the Norwegian software development industry, respondents agreed that the success of their companies' products depended upon usability [15]. Similar conclusions were drawn from another study of current Malaysian practices in UX and usability. However, whilst many respondents agreed on the importance of UX and usability, they held usability to be more important than UX [16]. There has only been one study in Saudi Arabia of how IT professionals perceive HCI, that by Majrashi and Al-Wabil [7]. The results of that study showed a higher than expected recognition of the importance of HCI. Despite a growing body of literature on UX design and UCD methodologies in research contexts in the Arab world, the understanding of the practitioners' perspective remains limited.

Only a limited amount has been written about the challenges faced by UX processes in countries other than the USA and in Europe. Indian UCD practice was discussed by Henry [17]. According to him, the filed in the country is facing the same usability misconceptions that exist in some other parts of the world. However, he highlighted three main myths that he saw as responsible for the most damage to software development in India:

- "Pretty screens are all you need;"

- "I can design on my own; just give me some guidelines;” and

- "Usability is about testing."

IT development in Korea has also encountered similar misconceptions, according to Ji and Yun [14], which led to resistance to adopting rigorous user research or considering UCD/usability studies in the design process. As far as Saudi Arabia is concerned, it is not clear what challenges face UX practice. A key objective of the present study was to identify these UX challenges.

\section{METHOD}

\section{A. Survey}

The study was conducted using the questionnaire as a data gathering tool. The choice of a questionnaire as the most appropriate data collection tool for this study was made because it allows large volumes of data to be collected quickly, and it is widely recognized by respondents and can be administered easily [18]. The questionnaire used in this study was designed based on that used by Sauro, Johnson, and Meenan [10], mentioned earlier, and comprised 30 questions in eleven sections. The first section focused on the respondents' demographics and experience with UX (i.e., age, gender, educational background, current role with their employer, and number of years' experience with UX). The second section included questions about the company the respondents working at (e.g., staff numbers and product type). The remaining nine sections corresponded to the other nine domains set out by Sauro, Johnson, and Meenan [10]. The format of the questions varied, including, for instance, multiple choice and Likert-type scales. It was important to ensure the order of presentation of questions did not affect responses (e.g., survey fatigue can result in lower ratings in later questions). Accordingly, the order in which sections three to eleven was presented was randomized.

\section{B. Sampling}

One of the challenges most often reported in this type of research is the identification of organizations engaged in software development. The study population was defined as all organizations with an involvement in the development of software (public or private, professional or not) in Saudi Arabia. The respondents targeted were those IT practitioners in such organizations, whose jobs involved softwaredevelopment environments.

There has been no previous attempt to establish a population of organizations involved with software development, so that respondents were contacted via various channels. The invitation and questionnaire were also posted on social media to reach further IT practitioners, particularly those in private companies with no mailing list accessible. The invitation emphasized that it was aimed at IT practitioners working for an organization involved in software development. It also defined UX and provided a link to more information on the concept. The invitation also advised potential respondents that they would be involved in the study voluntarily and that they would be able at any time to withdraw their participation. To encourage responses, respondents was not asked to identify the name of their organization, as respondents may have some concern about releasing specific information about their organization.

Both questionnaire and invitation were circulated in English as well as Arabic, to reach a wider population and achieve a higher response rate. Approximately half of the ICT professionals in the sector in Saudi Arabia are not nationals of the country [7]. In the event, the English version was used by approximately $34 \%$ of those who responded. To guarantee clarity, both versions (English and Arabic) were tested by three people as a pilot, with no issues identified. Google Forms was used to host the questionnaire on-line.

\section{RESULTS AND DISCUSSION}

\section{A. Individual Profiles}

75 respondents provided complete questionnaires. To identify if there was more than one response from the same organization, respondents' e-mail addresses was checked for those who used their organization's e-mail servers and respondents' answers were compared to specific questions in the organization profile section. Overall, it was confirmed that respondents could be from at least 73 different organizations. It was also determined that some of the large organizations, especially in the public sector, were represented in the sample based on the organization e-mail address provided voluntarily by some respondents.

$66.66 \%$ of respondents were between 30 and 39 years of age. The remainder (33.34\%) were between 21 and 29 . Approximately $11 \%$ were female. All of the respondents were qualified to Bachelor's degree level, with major subjects given as computer science (50 respondents), behavioral science (17 
respondents), and design (8 respondents). The job roles reported were product or project manager (26 respondents), developer (16 respondents), information architect (10 respondents), UX researcher (8 respondents), UX/UI designer (8 respondents), and other (7 respondents). There was a fair experience of UX reported (Fig. 1). The results demonstrate a good level of UX understanding among practitioners, which means that it would be worth considering their assessments of their organizations' level of UX maturity.

\section{B. Organizational Profiles}

The organizations represented in the sample varied in size, from just a few employees to more than 255 (see Table I). Only five respondents were employed by specialist UX companies, which suggests that there is a limited number of firms in the country which specialize in UX or consult in the field.

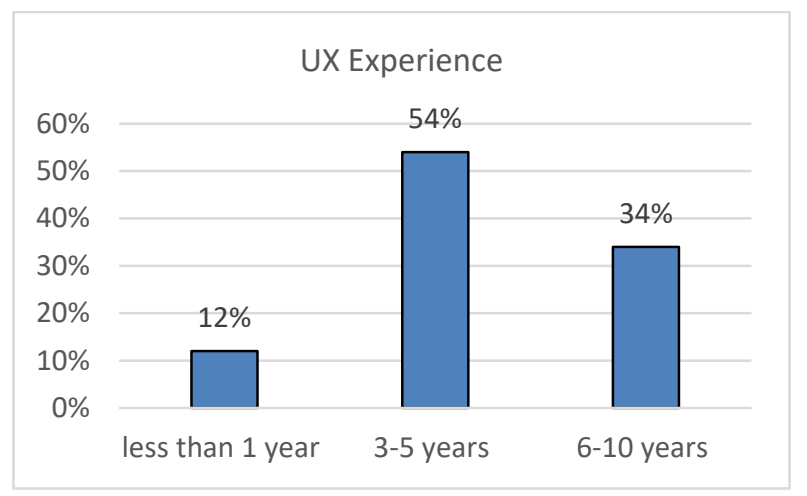

Fig. 1. Respondents' UX Experience.

TABLE I. ORGANIZATION PROFILES

\begin{tabular}{|c|c|c|}
\hline \multirow{3}{*}{ Sector } & Government & 29 \\
\hline & Private & 36 \\
\hline & Semi-government & 10 \\
\hline \multirow{7}{*}{ Category } & Software & 26 \\
\hline & Education & 9 \\
\hline & Health and medicine & 7 \\
\hline & E-commerce & 9 \\
\hline & Usability and UX & 5 \\
\hline & Retail & 4 \\
\hline & Other & 15 \\
\hline \multirow{4}{*}{ Size } & Large: $250+$ employees & 33 \\
\hline & Medium: 50-249 & 25 \\
\hline & Small: 10-49 & 11 \\
\hline & Micro: $1-9$ & 6 \\
\hline \multirow{3}{*}{$\begin{array}{l}\text { Type of } \\
\text { products }\end{array}$} & $\mathrm{B} 2 \mathrm{~B}$ & 28 \\
\hline & Internal tools & 14 \\
\hline & Consumer products or services & 63 \\
\hline \multirow{4}{*}{ Platform } & Mobile application & 63 \\
\hline & Web or cloud-based & 49 \\
\hline & Desktop software & 42 \\
\hline & Hardware or physical products & 7 \\
\hline
\end{tabular}

The projects run by the organizations represented in the sample were software products or services aimed at consumers. This corroborates the shift in Saudi Arabia, reported by CITC, to in-house IT development departments, from reliance on outsourced provision and the adaptation of software available commercially [5]. A variety of platforms are employed in the organizations represented, but mobile, web and desktop applications predominate. The diversity seen in organizational profiles seems to correspond to Saudi Arabia's wide organizational range.

\section{Estimated Maturity}

$56 \%$ of respondents in the sample perceived organization to be at the "Integrated" level of UX maturity, where UX processes are consistently integrated within product development (Fig. 2). It is interesting that no respondents considered their organizations to be at the "Unrecognized" level, where UX is not considered an issue and the user interface is mostly designed by developers, nor the "Ad hoc" level, where UX as an issue is recognized, but UX methods are not consistent.

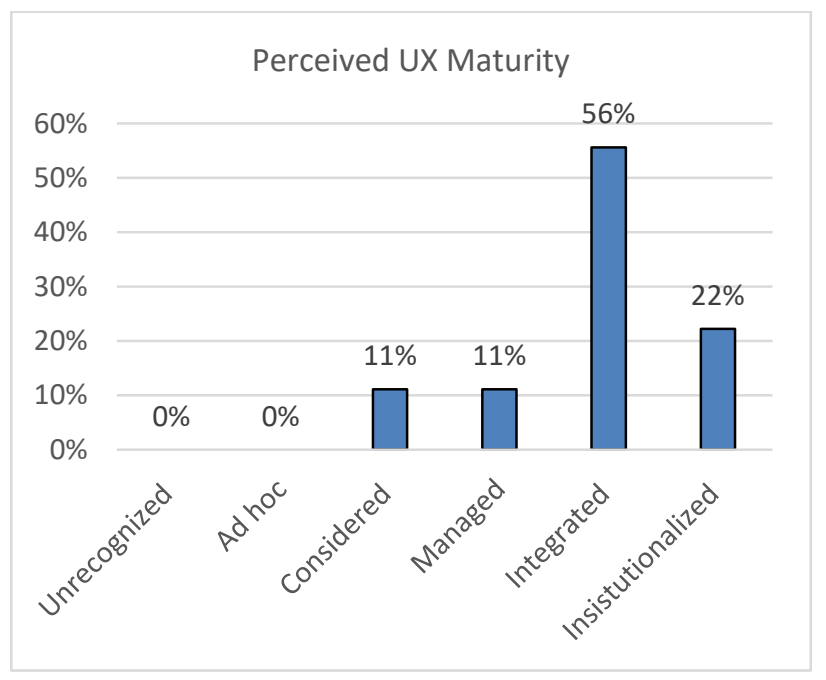

Fig. 2. Respondents' Perceptions of Organisational UX Maturity.

\section{UX Staffing}

Developers were better represented than either designers or researchers across organizations (see Fig. 3). 33\% of respondents indicated a ratio of approximately 1 designer to 610 developers, and 22\% reporting 1 to every 11-20. There was even more consensus when comparing designers to researchers, with $33.3 \%$ of respondents indicating a ratio of 1 researcher to every 5 or fewer designers. This finding is in line with that of [10], who assess UX maturity in US and found that there are approximately 1 designer to 11-20 developers, 1 researcher to every 5 or fewer designers.

\section{E. UX Research Methods}

Respondents were presented with a list of thirty UX methods and activities and asked to indicate which of these were employed in the software development environments within their organizations. Definitions of the thirty methods were provided for respondents. These were mostly taken from the literature (such as Hudson [19]). The respondents were 
also free to report methods additional to those given on the questionnaire. The methods and the frequency of their use was reported are shown in Table II. Although IT professionals seem to have some familiarity with various UX methods, the most frequently reported methods used by respondents were prototyping, task analysis, and heuristic evaluation.

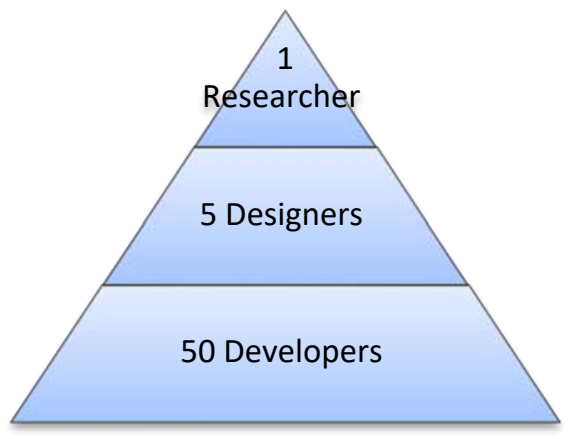

Fig. 3. Most Frequent Ratio of Researchers to Developers to Designers.

TABLE II. UX METHODS USED IN SOFTWARE-DEVELOPMENT ENVIRONMENTS

\begin{tabular}{|l|l|l|}
\hline No. & UX methods & Frequency \\
\hline 1 & Accessibility expert reviews & 12 \\
\hline 2 & Accessibility testing & 8 \\
\hline 3 & Analyze web metrics/logs & 14 \\
\hline 4 & Benchmarking or competitive studies & 24 \\
\hline 5 & Call center user feedback & 22 \\
\hline 6 & Card sorting & 25 \\
\hline 7 & Conceptual design & 8 \\
\hline 8 & Content strategy & 18 \\
\hline 9 & Content creation & 16 \\
\hline 10 & Contextual inquiry & 9 \\
\hline 11 & Creating prototypes (high-fidelity) & 52 \\
\hline 12 & Creating prototypes (wireframes or low-fidelity) & 45 \\
\hline 13 & Ethnography & 0 \\
\hline 14 & Eye tracking & 11 \\
\hline 15 & Focus groups & 16 \\
\hline 16 & Heuristic or expert review & 26 \\
\hline 17 & Information architecture & 18 \\
\hline 18 & Interface / interaction design & 33 \\
\hline 19 & Market research & 15 \\
\hline 20 & Personas \& user profiles & 28 \\
\hline 21 & Project management & 17 \\
\hline 22 & Requirements gathering & 28 \\
\hline 23 & Satisfaction surveys & 3 \\
\hline 24 & Strategy or strategic consulting & 12 \\
\hline 25 & Surveys or other online research & 14 \\
\hline 26 & Task analysis & 1 \\
\hline 27 & Technical writing & 16 \\
\hline 28 & Usability testing & 41 \\
\hline 29 & User research (e.g. interviews \& surveys) & 14 \\
\hline 30 & UX / Design Workshops & \\
\hline
\end{tabular}

Table III has been adapted from the work of [7] and [14] in order to illustrate the ten UX methods most used, according to the present study and other similar studies. Of these top ten methods used in Saudi Arabia, three have also been identified elsewhere in studies of IT-development practitioners, notably Korea [14], Europe and the USA [13], and across 14 countries (including the USA) [19]. The ways in which UX methods were applied to products was interesting to observe. Even though most respondents (61\%) reported that they had a standards set of methods, these were applied flexibly according to the needs of the project in hand (see Fig. 4).

Respondents were asked for the UX resources available for use in their organizations. The most frequently reported resources were user panel access and the provision of prototypes for participants (see Table IV).

TABLE III. The 10 Most Used UX Methods

\begin{tabular}{|c|c|c|c|c|}
\hline \multirow{2}{*}{$\begin{array}{l}\text { Ran } \\
\mathbf{k}\end{array}$} & $\begin{array}{l}\text { Our study } \\
\text { results }\end{array}$ & Ji and Yun [14] & $\begin{array}{l}\text { Vredenbur } \\
\text { g et al. [13] }\end{array}$ & Hudson [19] \\
\hline & $\begin{array}{l}\text { Saudi } \\
\text { Arabia }\end{array}$ & Korea & $\begin{array}{l}\text { US and } \\
\text { Europe }\end{array}$ & $\begin{array}{l}\text { US and other } \\
\text { countries }\end{array}$ \\
\hline 1 & Prototyping & Task analysis & $\begin{array}{l}\text { Iterative } \\
\text { design }\end{array}$ & $\begin{array}{l}\text { Informal } \\
\text { usability testing }\end{array}$ \\
\hline 2 & Task analysis & $\begin{array}{l}\text { Evaluation of } \\
\text { existing system }\end{array}$ & $\begin{array}{l}\text { Usability } \\
\text { evaluation }\end{array}$ & $\begin{array}{l}\text { User } \\
\text { analysis/profilin } \\
\text { g }\end{array}$ \\
\hline 3 & $\begin{array}{l}\text { Interface / } \\
\text { interaction } \\
\text { design }\end{array}$ & $\begin{array}{l}\text { User } \\
\text { analysis/profilin } \\
\text { g }\end{array}$ & $\begin{array}{l}\text { Task } \\
\text { analysis }\end{array}$ & $\begin{array}{l}\text { Evaluation of } \\
\text { existing system }\end{array}$ \\
\hline 4 & $\begin{array}{l}\text { Personas \& } \\
\text { user profiles }\end{array}$ & Surveys & $\begin{array}{l}\text { Informal } \\
\text { expert } \\
\text { review }\end{array}$ & $\begin{array}{l}\text { Low-fidelity } \\
\text { prototyping }\end{array}$ \\
\hline 5 & $\begin{array}{l}\text { Requirements } \\
\text { gathering }\end{array}$ & $\begin{array}{l}\text { Heuristic/Expert } \\
\text { evaluation }\end{array}$ & $\begin{array}{l}\text { Field } \\
\text { studies } \\
\text { (contextual } \\
\text { inquiry) } \\
\end{array}$ & $\begin{array}{l}\text { Expert } \\
\text { (heuristic) } \\
\text { usability } \\
\text { evaluation } \\
\end{array}$ \\
\hline 6 & $\begin{array}{l}\begin{array}{l}\text { Heuristic or } \\
\text { expert review }\end{array} \\
\end{array}$ & Scenarios of use & $\begin{array}{l}\text { Focus } \\
\text { groups }\end{array}$ & $\begin{array}{l}\text { Task } \\
\text { identification }\end{array}$ \\
\hline 7 & $\begin{array}{l}\text { Benchmarkin } \\
\text { g or } \\
\text { competitive } \\
\text { studies }\end{array}$ & $\begin{array}{l}\text { Navigation } \\
\text { design }\end{array}$ & $\begin{array}{l}\text { Formal } \\
\text { heuristic } \\
\text { evaluation }\end{array}$ & $\begin{array}{l}\text { Navigation } \\
\text { design }\end{array}$ \\
\hline 8 & Card sorting & $\begin{array}{l}\text { Usability } \\
\text { checklists }\end{array}$ & $\begin{array}{l}\text { Prototype } \\
\text { without user } \\
\text { testing }\end{array}$ & Scenarios of use \\
\hline 9 & $\begin{array}{l}\text { Call center } \\
\text { user feedback }\end{array}$ & $\begin{array}{l}\text { Focus-group } \\
\text { interviews }\end{array}$ & $\begin{array}{l}\text { User } \\
\text { interviews }\end{array}$ & $\begin{array}{l}\text { Set usability } \\
\text { requirements }\end{array}$ \\
\hline 10 & $\begin{array}{l}\text { Information } \\
\text { architecture }\end{array}$ & $\begin{array}{l}\text { Lab usability } \\
\text { testing }\end{array}$ & Surveys & $\begin{array}{l}\text { Visual interface } \\
\text { design }\end{array}$ \\
\hline
\end{tabular}

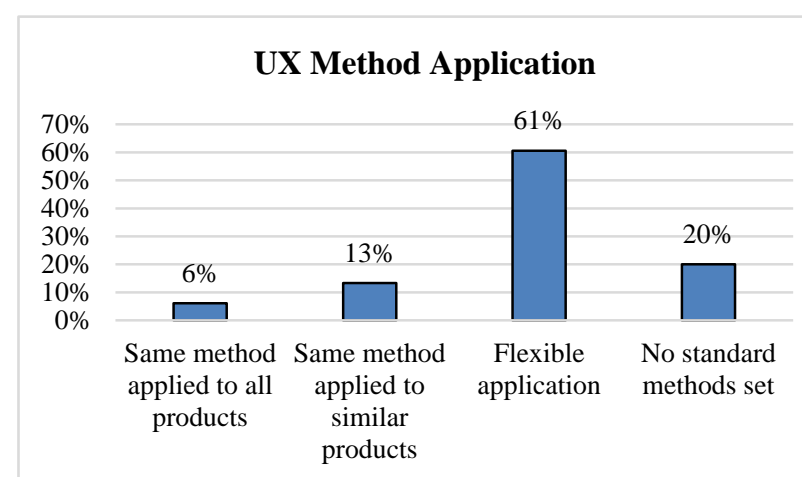

Fig. 4. UX Method Application. 
TABLE IV. UX RESOURCES

\begin{tabular}{|l|l|}
\hline UX resources & Frequency \\
\hline A dedicated space for usability testing (e.g., research lab) & 18 \\
\hline A one-way mirror for observation & 3 \\
\hline Video feeds for observation & 20 \\
\hline Access to user participant panels & 58 \\
\hline Prototypes to provide to participants & 56 \\
\hline Communication tools (intercom, instant messaging, etc.) & 33 \\
\hline
\end{tabular}

\section{F. Leadership and Culture}

Participants' perceptions of their organizations' valuation of UX were elicited by asking them to rank the perceived value on a scale from one to seven, where the higher the number, the higher the perceived value. The results appear to indicate that UX's importance is recognized by IT practitioners: there was an above-average score from all respondents. 22\% gave the highest score, 33\% at level six. In the present study, it was observed that respondents who reported their estimation of UX maturity higher, also reported a higher perceived value of UX, demonstrating that buy-in throughout the organization is strongly linked to maturity.

\section{G. UX Integration/Application}

One of the key indicators of an organization's level of UX maturity is the level of integration UX has within the organization. The present study's results reveal that UX is most frequently assessed at the stages of prototyping and advanced design, and after product launch (see Table V). The degree of UX maturity influences UX practices in an organization as well. Those respondents who gave higher maturity ratings for their organizations also reported UX evaluation at more stages.

Respondents were also asked how end-users were involved in product development. The most frequent stage for end-user involvement was prototyping (see Table VI). Significantly, the involvement of end-users at the prototyping stage was at a higher level in organizations rated higher for maturity.

\section{H. Training and Skills}

Respondents were also asked concerning the time and funding provided for UX education and training by their organizations. Almost $67 \%$ of participants reported having no funding available, and $78 \%$ reported having no time provided by their employer for UX education or training.

\section{Business and Product Success Metrics}

Respondents were asked to indicate the level of success experienced by their organization on a scale of one to seven, with higher numbers for more successful organizations. It is of interest that $75 \%$ of respondents perceived their organizations to be neutral in terms of success, $25 \%$ above average. It is possible that this is attributed to the time the survey was carried out, during the COVID-19 pandemic, which has affected businesses and other organizations very badly. Respondents were also asked to rate product development success, on a scale of one to five. Half believed that more than $50 \%$ of products made it at least as far as launch (see Fig. 5).

\section{J. UX Budget and Resources}

About $56 \%$ of participants reported having a dedicated budget for UX, whereas 33\% reported having none. A few reported not having a dedicated budget, but that discretionary funding could be requested.

\section{K. Challenges and Future Directions}

The questionnaire's final section asked about challenges currently facing UX. Table VII shows the obstacles and how often they were reported. The issues raised most frequently were those of UX consistency enhancement and collaboration across departments and between teams. It is, therefore, vital to follow specific, established rules of design in order guarantee a product has a seamless experience overall. Furthermore, it is important for IT managers to ensure that UX's importance and its impact are clear to their teams. Respondents from more than $75 \%$ of organizations represented in the sample reported a lack of UX training to an adequate level. It is clear that more UX training programs need to be provided for practitioners. It would also be appropriate to provide developers with training tailored to the context of their language and culture, so that they can understand and become proficient in UX and UCD. Notwithstanding this, respondents did express optimism for UX's future, feeling that UX budgets would increase and that job opportunities in the field would expand.

TABLE V. UX AsSESSMENT duRING PROduct DeVEloipemnt

\begin{tabular}{|l|l|}
\hline Stages of product & Frequency \\
\hline Concept generation & 32 \\
\hline Initial design/development & 26 \\
\hline Prototyping/advanced design & 68 \\
\hline Immediately prior to launch & 12 \\
\hline Post-launch & 66 \\
\hline
\end{tabular}

TABLE VI. USER INVOLVEMENT DURING PRODUCT DEVELOIPEMNT

\begin{tabular}{|l|l|}
\hline Stages of product & Frequency \\
\hline Concept generation & 29 \\
\hline Initial design/development & 35 \\
\hline Prototyping/advanced design & 40 \\
\hline Immediately prior to launch & 9 \\
\hline Post-launch & 7 \\
\hline Never & 4 \\
\hline
\end{tabular}

\section{Product Development Success}

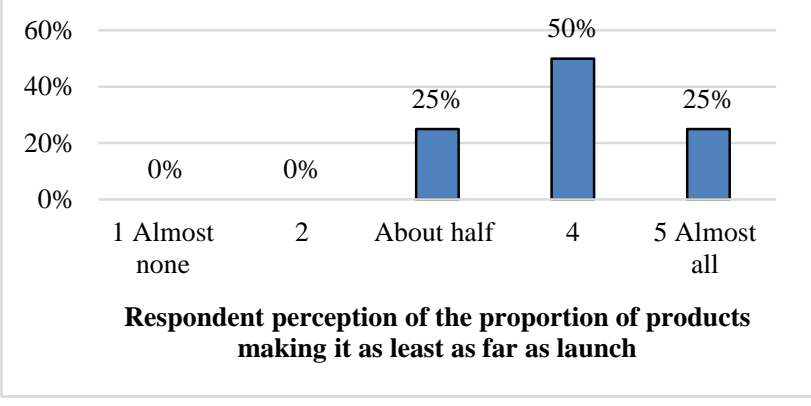

Fig. 5. Success of Product Development. 
TABLE VII. CHALLENGES FACING UX PROCESS

\begin{tabular}{|l|l|}
\hline UX challenges & Frequency \\
\hline Handing off designs to developers & 13 \\
\hline Collaborating between teams & 34 \\
\hline Clarifying requirements & 6 \\
\hline Securing appropriate UX budget or resources & 17 \\
\hline Testing designs with end-users & 20 \\
\hline Improving UX consistency & 55 \\
\hline Legacy technology & 19 \\
\hline Getting buy-in or understanding from executives & 4 \\
\hline Collaborating across departments & 42 \\
\hline $\begin{array}{l}\text { Evolving UX and design alongside products (multiple } \\
\text { testing time points) }\end{array}$ & 4 \\
\hline
\end{tabular}

\section{CONCLUSION}

Successful software development is becoming increasingly dependent upon UX design. It affects employee productivity, and whether a service or a product retains user engagement. Organizations must, therefore, ensure the maturity of their UX work. Yet, there are still organizations which do not assign high value to UX and where there is limited UX maturity. This paper reports the results of a survey of the current state of UX maturity in Saudi Arabian software development environments, involving 75 practitioners. A range of aspects was covered. In general, a higher awareness of the value of UX than expected was found. Practitioners also expressed a higher perception of their organizations' UX maturity than anticipated, with most considering it to be at an 'integrated' level. The study also reveals the UX methods most frequently employed (i.e., task analysis, prototyping and heuristic evaluation). The results also show that UX evaluation and the involvement of users occur at various product development stages, especially at the phase of prototyping. The main challenges for UX process were identified as collaboration across departments and between teams, and improving the consistency of UX. Future work is still required to confirm the results of the current study and reveal any other obstacles facing UX work in software development environments in Saudi Arabia.

\section{ACKNOWLEDGMENT}

The author would like to thank all those who take part in the survey. Thanks also the anonymous reviews for their invaluable comments.

\section{REFERENCES}

[1] Rukonić, Luka, Vincent Kervyn de Meerendré, and Suzanne Kieffer. "Measuring UX capability and maturity in organizations." In International Conference on Human-Computer Interaction, pp. 346365. Springer, Cham, 2019.

[2] Communications and Information Technology Commission (CITC): annual report of Communications and Information Technology
Commission (2016). 2016. Avaialbe at: https://www.citc.gov.sa/en/ mediacenter/annualreport/Documents/PR_REP_012Eng.pdf. Accessed 22 July 2020.

[3] CITC: Indicators ICT KSA: end of Q3. 2018. Avaialbe at: https://www.citc.gov.sa/en/reportsandstudies/indicators/Indicators\%20 of\%20Communications\%20and\%20Information\%20Techn/ICTIndicators -Q32018En.pdf Accessed 22 July 2020.

[4] Saudi Vision 2030: National transformation program 2020. Avaialbe at: https://vision2030.gov.sa/sites/default/files/attachments/NTP\%20Engli sh\%20Public\%20Document_2810.pdf Accessed 22 July 2020.

[5] CITC: IT report (2009). 2009 Avaialbe at: https://www.citc.gov.sa/ en/mediacenter/annualreport/Documents/PR_REP_001E.pdf . Accessed 22 July 2020.

[6] CITC: ICT workforce report: 2015 (2015). http://www.citc.gov.sa/en/ reportsandstudies/Reports/Documents/ICTWorkforce_en.pdf . Accessed 22 July 2020.

[7] Majrashi, Khalid, and Areej Al-Wabil. "HCI Practices in SoftwareDevelopment Environments in Saudi Arabia." In International Conference on Cross-Cultural Design, pp. 58-77. Springer, Cham, 2018.

[8] Anchahua, Maritza Cieza, Luis Vives Garnique, and Javier Alvarez Tarazona. "User Experience Maturity Model for Ecommerce Websites." In 2018 Congreso Internacional de Innovación y Tendencias en Ingeniería (CONIITI), pp. 1-6. IEEE, 2018.

[9] Möller, Josefine. "Actions for Increasing an Organization's UX Maturity." (2018).

[10] Sauro, Jeff, Kristin Johnson, and Chelsea Meenan. "From snake-oil to science: measuring UX maturity." In Proceedings of the 2017 CHI Conference Extended Abstracts on Human Factors in Computing Systems, pp. 1084-1091. 2017.

[11] Young, Scott WH, Zoe Chao, and Adam Chandler. "User Experience Methods and Maturity in Academic Libraries." Information Technology and Libraries 39, no. 1 (2020).

[12] Earthy, Jonathan. "Usability maturity model: Human centredness scale." INUSE Project deliverable D 5 (1998): 1-34.

[13] Vredenburg, Karel, Ji-Ye Mao, Paul W. Smith, and Tom Carey. "A survey of user-centered design practice." In Proceedings of the SIGCHI conference on Human factors in computing systems, pp. 471-478. 2002.

[14] Ji, Yong Gu, and Myung Hwan Yun. "Enhancing the minority discipline in the IT industry: A survey of usability and user-centered design practice."International Journal of Human-Computer Interaction 20, no. 2 (2006): 117-134.

[15] Bygstad, B., Ghinea, G., Brevik, E.: Software development methods and usability: perspectives from a survey in the software industry in Norway. Interact. Comput. 20(3), 375-385 (2008). https://doiorg.sdl.idm.oclc. org/10.1016/j.intcom.2007.12.001.

[16] Hussein, Idyawati, Murni Mahmud, and Abu Osman Md Tap. "A survey of user experience practice: a point of meet between academic and industry." In 2014 3rd International Conference on User Science and Engineering (i-USEr), pp. 62-67. IEEE, 2014.

[17] Henry, P.: Advancing UCD while facing challenges working from offshore. Interactions 10(2), 38-47 2003. https://doiorg.sdl.idm.oclc.org/10.1145/637848.637861.

[18] Lazar, Jonathan, Jinjuan Heidi Feng, and Harry Hochheiser. Research methods in human-computer interaction. Morgan Kaufmann, 2017.

[19] Hudson, W.: Toward unified models in user-centered and objectoriented design. In: Van Harmelen, M. (ed.) Object Modeling and User Interface Design: Designing Interactive Systems, pp. 313-362. AddisonWesley Longman, Boston. 2001. 